Jong-Ho Choi MD, G. Alec Rooke MD PhD, Sai-Chuen Wu MD, Michael J. Bishop MD

\title{
Reduction in post- intubation respiratory resistance by isoflurane and albuterol
}

Purpose: This study examined the bronchodilating effects of 0.6 MAC and 1.1 MAC isoflurane (ISF) on respiratory system resistance $\left(R_{r s}\right)$ following tracheal intubation and determined whether albuterol supplements that effect.

Methods: Sixty-seven adult patients were anaesthetized with $2 \mu \mathrm{g} \cdot \mathrm{kg}$ ' fentanyl and $5 \mathrm{mg} \cdot \mathrm{kg}$ ' thiopentone and their tracheas intubated following administration of $1 \mathrm{mg} \cdot \mathrm{kg}$ ' succinylcholine. Respiratory system resistance was measured following intubation and the patients then randomized to receive either 1. I MAC ISF in oxygen or 0.6 MAC ISF in $50 \%$ nitrous oxide and oxygen. Ten minutes later, $R_{r s}$ was again measured. Patients were then further randomized to receive albuterol or a placebo using incremental doses of 2, 5, and 10 puffs (albuterol puff = $90 \mu \mathrm{g}$ ) delivered via a metered dose inhaler at ten minute intervals.

Results: Isoflurane at I.I MAC decreased post-intubation $R_{r s}$ by $23 \pm 5 \%$ (mean \pm sem) whereas the decrease was only $7 \pm 5 \%$ for 0.6 MAC ISF $(P<0.01)$. Two puffs of albuterol resulted in a further decrease of $12 \pm 3 \%$ (mean $\pm \mathrm{sem}$ ) in $R_{r s}$ compared with a $2 \pm 4 \%$ decrease in the placebo groups $(P<0.05)$. Additional puffs of albuterol resulted in no further changes in $R_{r}$.

Conclusion: We conclude that following tracheal intubation the reduction in $\mathrm{R}_{\mathrm{s}}$ produced by ISF is highly concentration dependent. Albuterol results in a small further reduction in $R_{\text {. }}$.

Objectif : Étudier l'effet bronchodilatateur de l'isoflurane (ISF) à 0,6 MAC et à 1, I MAC sur la résistance du système respiratoire $\left(R_{T S}\right)$ après l'intubation trachéale et déterminer si l'albutérol amplifie cet effet.

Méthodes : Soixante-sept adultes anesthésiés au fentanyl $2 \mu \mathrm{g} \cdot \mathrm{kg}{ }^{\prime}{ }^{\prime}$ et au thiopentone $5 \mathrm{mg} \cdot \mathrm{kg}{ }^{\prime}{ }^{\circ}$ ont été intubés après l'administration de succinylcholine $\mathrm{I} \mathrm{mg} \cdot \mathrm{kg}$ ' La résistance du système respiratoire a été mesurée après l'intubation et les patients ont été répartis aléatoirement pour recevoir soit ISF 1.I MAC ou ISF 0.6 MAC dans le protoxyde d'azote $50 \%$ en oxygène. Dix minutes plus tard, la $R_{T S}$ a été mesurée de nouveau. Les patients ont été de nouveau répartis aléatoirement pour recevoir de l'albutérol ou un placebo en dose fractionnées de 2, 5 et 10 bouffées (une bouffée d'albutérol $=90 \mu \mathrm{g}$ ) délivrées par un inhalateur gradué à dix minutes d'intervalles. Résultats : Ľisoflurane à 1.1 MAC diminue la $R_{T S}$ de $23 \pm 5 \%$ (moyenne \pm sem) alors que la diminution n'était que de $7 \pm 5 \%$ avec l'isoflurane à $0.6 \mathrm{MAC}(P<0.01)$. Deux bouffées d'albutérol ont provoqué une nouvelle baisse de $12 \pm 3 \%$ (moyenne \pm sem) de la $R_{\text {Ts }}$ comparativement à $2 \pm 4 \%$ dans le groupe placebo $(P<0.05)$. Les bouffées additionnelles d'albutérol n'ont pas modifié davantage la $R_{T 5}$.

Conclusion : Après une intubation trachéale, la réduction de la $R_{T S}$ produite par l'isoflurane dépend fortement de sa concentration. L'albutérol provoque une petite réduction additionnelle.

\footnotetext{
From the Department of Anesthesiology, University of Washington School of Medicine, Seartle and Department of Anesthesiology, Chang Gung Medical Hospital and Chang Gung College of Medicine and Technology, Taiwan, ROC.

Address correspondence to: Michael J. Bishop, MD Seattle VAMC 112A, 1660 South Columbian Way, Seattle, WA 98108.

Phone: (office) 206-764-2052; Fax: 206-764-2914; E-mail: bish@u.washington.edu Accepted for publication, March 29, 1997.
} 


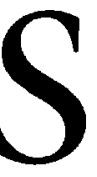

EVERE bronchospastic episodes during anaesthetic care occur most often following intubation of the trachea and occur even in patients without previous history of airway hyperreactivity. ${ }^{1}$ Respiratory resistance also increases after intubation even in normal volunteers ${ }^{2}$ and both $B_{2}$-adrenergic agonists and cholinergic antagonists have been demonstrated to ameliorate this response. ${ }^{3,4}$

Although intubation of the trachea provides a potent stimulus to bronchoconstriction, it is generally followed in the operating room by the delivery of inhalational anaesthetics, which are potent bronchodilators. ${ }^{5}$ Whenever the increase in respiratory resistance is high enough to be clinically evident, clinicians often consider additional treatment with an inhaled $B_{2}$-adrenergic agonist. In dogs, the addition of the $B_{2}$-adrenergic agonist albuterol during halothane anaesthesia shifts the dose response curve to the right (less responsive) for histamine-induced bronchoconstriction, ${ }^{6}$ but no data exist in humans. Furthermore, it is difficult to know whether a dose-response curve to histamine mimics the expected responses to therapeutic agents following intubation-induced bronchomotor activity.

The purpose of the current study was to assess the concentration dependence of the bronchodilating effect of isoflurane following tracheal intubation and to assess whether albuterol provides further bronchodilation in the presence of isoflurane anaesthesia.

\section{Methods}

Written informed consent was obtained from 67 patients to participate in the study protocol approved by the Human Subjects Committees of the University of Washington School of Medicine and the Puget Sound Veterans Affairs Health Care System. Subjects were excluded if they were being treated with a $B_{2}-$ adrenergic agonist inhaler, corticosteroids, or theophylline. Peak expiratory flow (PEF) was measured prior to induction of anaesthesia. Anaesthesia was induced in all patients with $5 \mathrm{mg} \cdot \mathrm{kg}^{-1}$ thiopentone, 1 $\mathrm{mg} \cdot \mathrm{kg}^{-1}$ succinylcholine, and $2 \mu \mathrm{g} \cdot \mathrm{kg}^{-1}$ fentanyl $i v$ and the trachea then intubated with a cuffed endotracheal tube (ETT) with an inner diameter of 7.0-8.0 mm. Following intubation of the trachea, patients were paralysed with $0.1 \mathrm{mg} \cdot \mathrm{kg}^{-1}$ vecuronium $i v$ and the lungs were ventilated at a tidal volume of $10 \mathrm{ml} \cdot \mathrm{kg}^{-1}$ at a rate of eight bpm and an I:E ratio of 1:3. Inspiratory flow was set at $30 \mathrm{~L} \cdot \mathrm{min}^{-1}$.

Two minutes after intubation and prior to delivery of any inhalation anaesthetic, respiratory resistance $\left(\mathrm{R}_{\mathrm{rs}}\right)$ was measured and heart rate and blood pressure recorded. Patients were then randomized into two groups to receive either $0.6 \mathrm{MAC}$ end-tidal isoflurane with $\mathrm{N}_{2} \mathrm{O} 50 \%$ or to receive $1.1 \mathrm{MAC}$ end-tidal isoflurane in oxygen. Rapid over-pressure up to isoflurane $5 \%$ was used to achieve these concentrations as quickly as possible, generally within the first two minutes. The end-tidal concentration was then held stable. Ten minutes later, a second set of measurements was made and each group further randomized to receive either albuterol or a placebo via a metered dose inhaler (MDI) using a spacer (Aerochamber, Monaghan Medical, Plattsburgh, New York) connected between the Y-piece of the circuit and the endotracheal tube. Patients received two puffs from the MDI and measurements were repeated 10 min later. Following that measurement, five additional puffs were given and the measurements repeated $10 \mathrm{~min}$ later. Lastly, another 10 puffs were given (cumulative dose of 17 puffs) and a final measurement made 10 min later. This resulted in four groups - 1.1 MAC isoflurane with and without albuterol and 0.6 MAC isoflurane with and without albuterol.

Measurements of $R_{r s}$ were made using the isovolume method ${ }^{7}$ after correction for the resistance of the endotracheal tube as previously described. ${ }^{8}$ Prior to each patient the spirometer was calibrated for volume using a one litre syringe (Hans Rudolph Inc., Kansas City, MO). Using a pneumotachograph and personal computer, the ventilatory flow and pressure curves were sampled at $10 \mathrm{msec}$ intervals and the volume curve was determined by integration of the flow curve. The pressure drop across the endotracheal tube was excluded by first constructing a pressure-flow curve for both the 7.5 and $8.0 \mathrm{~mm}$ endotracheal tubes. For each measurement, the pressure drop across the tube for the flow noted was subtracted from the pressure measurements used during calculation, resulting in a value for $R_{r s}$ exclusive of the endotracheal tube. The isovolume method of resistance measurement is a technique applicable to mechanically ventilated patients and is based on measuring airway pressure and flow at identical volumes during inspiration and exhalation. Inspiratory pressure $(\mathrm{Pi})$ is a function of respiratory compliance $(\mathrm{C})$, inspiratory flow (Fi) and resistance (R). Expiratory pressure $(\mathrm{Pe})$ is a function of respiratory compliance $(C)$, expiratory flow (Fe) and resistance ( $\mathrm{R})$. Using $\mathrm{V}$ to represent lung volume above $F R C$, the equations are:

$\mathrm{Pi}=\mathrm{C} / \mathrm{V}+\mathrm{RFi}$ and

$\mathrm{Pe}=\mathrm{C} / \mathrm{V}-\mathrm{RFe}$

Subtracting these two equations yields:

$\mathrm{Pi}-\mathrm{Pe}=\mathrm{R}(\mathrm{Fi}+\mathrm{Fe})$ or $\mathrm{R}=(\mathrm{Pi}-\mathrm{Pe}) /(\mathrm{Fi}+\mathrm{Fe})$ 
This determination of $R_{r s}$ is influenced by both inspiratory and expiratory resistance. Measurements of end-tidal isoflurane were made using a Datex Capnomac (Datex, Tewksbury, MA). The predicted value for peak expiratory flow (PEF predicted) was used to normalize PEF.

Data are expressed as mean \pm SEM. Group comparisons for age, weight, height, pack-years of smoking, peak expiratory flow as a percent of predicted flow, and $\mathrm{R}_{\mathrm{rs}}$ immediately after intubation were performed with analysis of variance. Group comparisons for sex and ASA status were performed with the Chisquare statistic. Correlations between continuous variables were determined with regression analysis.

Group differences in $R_{r s}$ were detected with repeated measures analysis of variance with the betweensubject factors of high/low isoflurane concentration and the presence/absence of albuterol. More explicit examination of the individual effects of isoflurane and albuterol was also performed. The effect of isoflurane was determined by calculating the percent change in $\mathrm{R}_{\mathrm{rs}}$ between the post-intubation and post- isoflurane values of $R_{r s}$ for each subject:

(post-isoflurane $\mathrm{R}_{\mathrm{rs}}$ )-(post-intubation $\mathrm{R}_{\mathrm{rs}}$ )/(post-intubation $R_{r s}$ ). An unpaired $t$ test examined for differences between the percent change in $R_{r s}$ for the two isoflurane concentrations.
The effect of albuterol was determined by calculating the percent change in $\mathrm{R}_{\mathrm{s}}$ between the post- isoflurane and the post-two puffs of inhaler values of $R_{r s}$ for each subject:

(post-two puffs $\mathrm{R}_{\mathrm{r}}$ )-(post-isoflurane $\mathrm{R}_{\mathrm{s}}$ )/(post-isoflurane $\mathrm{R}_{\mathrm{rs}}$ ). Since the two albuterol and the two placebo groups were exposed to different isoflurane concentrations, the percent change in Rrs was analysed by factorial analysis using both isoflurane concentration and the presence/absence of albuterol as factors.

\section{Results}

There was no difference among the groups in height, weight, age, ASA class, or smoking history (Table I). Peak expiratory flow as a percentage of predicted did not differ among the groups (Table I) and was negatively correlated with the number of pack-years the patient had smoked $(P<0.01, r=-0.45)$. Only 18 of 67 patients had a percent of predicted peak expiratory flow to 1.0. Immediately after intubation $\mathrm{R}_{\mathrm{s}}$ averaged $10.3 \pm 0.5 \mathrm{~cm} \mathrm{H}_{2} \mathrm{O} \cdot \mathrm{L}^{-1} \cdot \mathrm{sec}$ and did not differ among the groups (Table II). The haemodynamic responses to the four regimens did not differ among the groups (Table III).

For all four groups there was a decrease in $\mathrm{R}_{\mathrm{rs}}$ after ten minutes of isoflurane $(P<0.05$ for each group)

TABLE I Baseline Characteristics by Group

\begin{tabular}{lcccc}
\hline & $(n=17) 1.1$ MAC ISF, & $(n=15) 1.1$ MAC ISF, & $(n=21) 0.6$ MAC ISF, & (n=14) 0.6 MAC ISF, \\
\hline & albuterol & placebo & albuterol & placebo \\
Malcs/Fcmales & $16 / 1$ & $15 / 0$ & $20 / 1$ & $14 / 0$ \\
Age(ycars) & $53 \pm 4$ & $59 \pm 3$ & $57 \pm 3$ & $57 \pm 3$ \\
Weight (kg) & $83 \pm 5$ & $84 \pm 5$ & $79 \pm 4$ & $91 \pm 5$ \\
Height (cm) & $175.3 \pm 1.1$ & $175.3 \pm 0.7$ & $175 \pm 0.7$ & $180.3 \pm 0.7$ \\
ASA & $2 \pm 0.1$ & $2 \pm 0.1$ & $2 \pm 0.1$ & $1.9 \pm 0.1$ \\
Smoking (pack years) & $36 \pm 8$ & $42 \pm 8$ & $40 \pm 8$ & $48 \pm 11$ \\
Peak Expiratory Flow & $92 \pm 4$ & $92 \pm 6$ & $84 \pm 3$ & $89 \pm 4$ \\
(\% of predicted) & & & & \\
\hline
\end{tabular}

Data are mean \pm sem.

TABLE II Raw data for $R_{\text {w }}$

\begin{tabular}{|c|c|c|c|c|c|}
\hline \multirow[t]{2}{*}{ Group } & \multicolumn{5}{|c|}{$\operatorname{Rrs}(\mathrm{cm} \mathrm{H} 2 \mathrm{O} \cdot L-J \cdot \mathrm{sec})$} \\
\hline & Post - ETT & Post. ISF & 2 Puffs & 7 puffs & 17 puffs \\
\hline 1.1 MAC ISF, albuterol & $11.3 \pm 1.1$ & $8.5 \pm 0.5$ & $7.3 \pm 0.5^{*}$ & $7.2 \pm 0.7^{\star}$ & $7.4 \pm 0.6^{*}$ \\
\hline 1.1 MAC ISF, placebo & $10.5 \pm 1.6$ & $6.8 \pm 1.1$ & $6.6 \pm 0.9$ & $6.4 \pm 0.7$ & $6.5 \pm 0.7$ \\
\hline 0.6 MAC ISF, albuterol & $9.0 \pm 0.7$ & $8.3 \pm 0.7$ & $7.3 \pm 0.6^{*}$ & $7.5 \pm 0.7^{\star}$ & $7.5 \pm 0.6^{*}$ \\
\hline 0.6 MAC ISF, placebo & $11.3 \pm 1.0$ & $10.0 \pm 1.0$ & $9.4 \pm 1.0$ & $8.8 \pm 1.0^{*}$ & $8.3 \pm 0.9^{*}$ \\
\hline
\end{tabular}

Data arc mean + sem. ${ }^{*} p<0.05$ vs post-ISF Rrs in same group.

(Post $-\mathrm{ETT}=\mathrm{R}_{\mathrm{rs}}$ following tracheal intubation) 
TABLE III Hemodynamic Measurements

\begin{tabular}{|c|c|c|c|c|c|c|c|c|c|c|}
\hline \multirow[t]{2}{*}{ Group } & \multicolumn{5}{|c|}{ Mean blood pressure $(\mathrm{mmHg})$} & \multicolumn{5}{|c|}{ Heart rate (beats-min.) } \\
\hline & Post - ETT & Post. ISF & 2 Puffs & 7 puffs & 17 puffs & Post. ETT & Post. ISF & 2 Puffs & 7 puffs & 17 puffs \\
\hline $\begin{array}{l}\text { 1.1 MAC ISF, } \\
\text { albuterol } \\
\text { 1.1 MAC ISF, }\end{array}$ & $112 \pm 8$ & $78 \pm 4$ & $74 \pm 3$ & $74 \pm 2$ & $78 \pm 4$ & $86 \pm 4$ & $77 \pm 4$ & $74 \pm 4$ & $75 \pm 4$ & $76 \pm 4$ \\
\hline $\begin{array}{l}\text { placebo } \\
0.6 \mathrm{MAC} \text { ISF, }\end{array}$ & $117 \pm 6$ & $81 \pm 6$ & $78 \pm 4$ & $77 \pm 3$ & $84 \pm 5$ & $86 \pm 4$ & $77 \pm 4$ & $75 \pm 4$ & $73 \pm 4$ & $75 \pm 5$ \\
\hline albuterol & $116 \pm 5$ & $86 \pm 5$ & $77 \pm 3$ & $78 \pm 3$ & $82 \pm 4$ & $83 \pm 3$ & $72 \pm 4$ & $63 \pm 2$ & $63 \pm 3$ & $64 \pm 3$ \\
\hline placebo & $117 \pm 5$ & $89 \pm 6$ & $79 \pm 4$ & $83 \pm 4$ & $84 \pm 5$ & $95 \pm 4$ & $75 \pm 4$ & $67 \pm 3$ & $65 \pm 3$ & $65 \pm 4$ \\
\hline
\end{tabular}

Data are mean $+\mathrm{sem}$. ISF $=$ isoflurane. 2 puffs, 7 puffs, and 17 puffs represent cumulative doses of albuterol or placebo.

(Post - ETT $=$ Post endotracheal intubation)

(Table II). When the percent change in $\mathrm{R}_{r s}$ was determined between the post-intubation and post-isoflurane conditions, those subjects who received 1.l MAC isoflurane demonstrated a greater percent decrease in $\mathrm{R}_{\mathrm{rs}}$ than the patients receiving 0.6 MAC isoflurane $/ \mathrm{N}_{2} \mathrm{O} 50 \%(23 \pm 5 \%$ decrease vs $7 \pm 5 \%$ decrease, $P=0.01$ ) (Figure 1).

Repeated measures analysis of variance for the collective data for $\mathrm{R}_{\mathrm{rs}}$ confirmed the significant difference in response between the two isoflurane concentrations $(P=0.005)$ but failed to demonstrate a significant effect of albuterol $(P=0.58)$. However, when the percent change in $R_{r s}$ was determined between the conditions of $10 \mathrm{~min}$ of isoflurane and two puffs of albuterol, those subjects who received two puffs of albuterol demonstrated a greater decrease in $\mathrm{R}_{\mathrm{rs}}$ than those who received placebo $(12 \pm 3 \%$ vs $2 \pm 4 \%, P=$ 0.03 ) (Figure 2). In the same analysis the isoflurane concentration did not influence the albuterol effect ( $P=0.64$ for the effect of isoflurane concentration). The subsequent doses of albuterol or placebo did not change Rrs except for the placebo group at 0.6 MAC isoflurane $(P=0.01$ by repeated measures analysis of variance of the 2,7 and 17 puffs data).

\section{Discussion}

Following tracheal intubation, $\mathrm{R}_{\mathrm{rs}}$ increases markedly. Much of this increase is due to the decrease in lung volume that occurs with induction of anaesthesia. ${ }^{9}$ Respiratory resistance also increases due to bronchoconstriction, presumably because of vagally mediated increases in bronchial muscle tone resulting from direct mechanical stimulation. Prophylactic administration of a $\beta_{2}$-adrenergic agonist will limit this response. ${ }^{3,4,10}$

Inhaled anaesthetics are effective in limiting bronchoconstriction induced by a wide variety of stimuli in animals and animal models. ${ }^{11}$ Mechanisms of bron- chodilation by inhaled agents include direct airway smooth muscle relaxation, ${ }^{5}$ blockade of vagal airway reflexes and augmentation of $B$-adrenergic tone. ${ }^{12}$ Because of the multiple mechanisms of action and the differing efficacy of bronchodilating agents in response to different stimuli, it is difficult to predict whether the effects of bronchodilators such as methylxanthines or $B_{2}$-adrenergic agonists will be additive with the bronchodilating effects of an inhaled anaesthetic. In a study of dose-response curves for histamine-induced bronchoconstriction in dogs, the addition of theophylline or atropine to halothane did not improve upon the response with halothane alone, but the addition of albuterol to halothane did reduce the bronchoconstriction response to histamine in comparison with halothane alone. ${ }^{6}$

The bronchodilating effects of isoflurane are well accepted clinically and have been studied in animals ${ }^{13}$ but there are few human studies ${ }^{14}$ and little data concerning concentration dependence. In a previous human study, we found that 1.l MAC isoflurane did not add to the bronchodilating effect of the $B_{2}$-adrenergic agonist fenoterol when fenoterol was given prior to intubation. ${ }^{9}$ However, we wondered whether the converse was true, that adding a $\beta_{2}$-adrenergic agonist would not supplement the effect of 1.1 MAC isoflurane. We also felt it important to study whether the effect might differ if albuterol treatment were added at a lower concentration of inhaled anaesthetic, since dog studies suggest that, at low concentrations, isoflurane is a relatively ineffective bronchodilator. ${ }^{15}$

We found that the dose response curve for isoflurane-induced bronchodilation was steep between 0.6 and 1.1 MAC, with a nearly four-fold greater reduction in $\mathrm{R}_{r s}$ at the higher dose. These human data for isoflurane dose-response are similar to previously reported dog data for histamine-induced bronchoconstriction. ${ }^{15}$ 


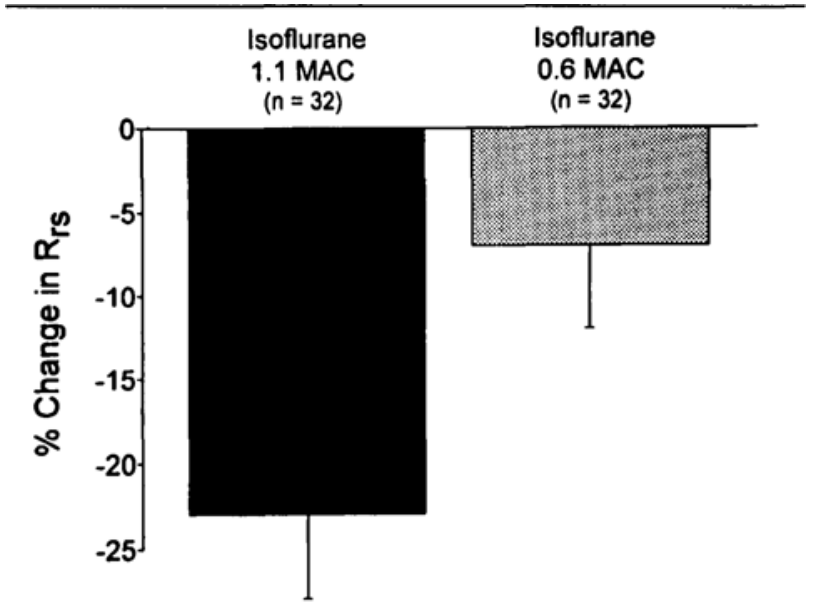

FIGURE 1 Decrease in respiratory system resistance $\left(R_{r}\right)$ by 1.1 vs. 0.6 MAC end-tidal concentration of isoflurane $(p=0.01$ between 1.1 and $0.6 \mathrm{MAC}$ ). Results are expressed as a percentage change from $R_{r s}$ after intubation.

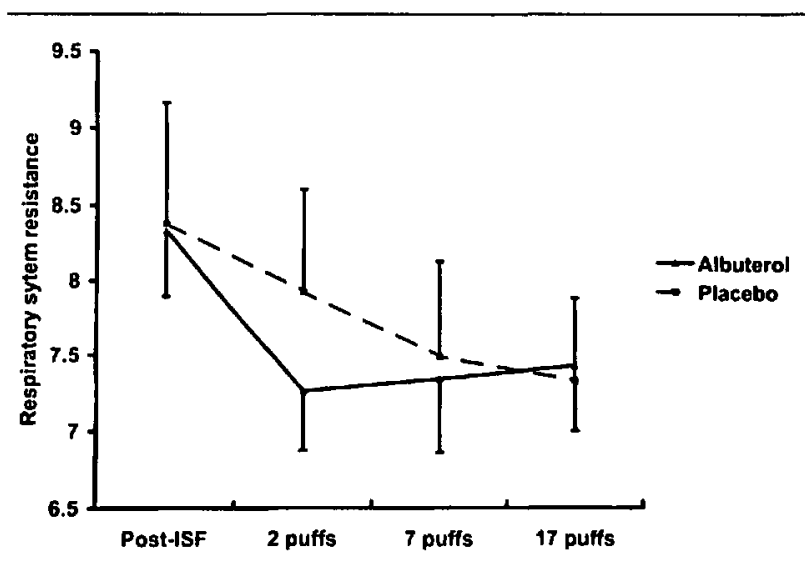

FIGURE 2 Respiratory system resistance ( $\mathrm{cm} \mathrm{H}_{2} \mathrm{O} \cdot \mathrm{L}^{-1} \cdot \mathrm{sec}^{-1}$ ) for albutcrol (solid line) and placebo (dashed line) treated patients after 10 minutes of isoflurane (1.1 and 0.6 MAC end-tidal concentration combined) and following each dose of albuterol. The decline after two puffs of albuterol was significantly different from the decline after two puffs of placebo $(p=0.03)$ but further doses of albuterol produced no additional decreases in $\mathrm{R}_{\mathrm{r}}$. By ten minutes later (after the 7 puffs) there was no difference between placebo and albuterol treated patients.

The initial benefit of albuterol in the presence of isoflurane was statistically significant compared with placebo. However, the $10 \%$ reduction beyond that of placebo is of questionable clinical importance. Furthermore, the same reduction in Rrs was achieved with ten more minutes of isoflurane plus placebo.

The inability of albuterol administration in excess of two puffs to achieve further reductions in $R_{r s}$ suggests that either the dose response curve for albuterol is rela- tively flat or that maximal bronchodilation was achieved at the lowest dose of albuterol in combination with isoflurane. In awake asthmatics, there is minimal additional benefit after two puffs of albuterol. ${ }^{16,17}$ Furthermore, a comparable decline in Rrs occurred in the placebo group after $\mathbf{3 0} \mathrm{min}$ of isoflurane, suggesting that isoflurane alone is capable of achieving comparable bronchodilation, albeit requiring a bit more time.

We previously studied whether isoflurane produced bronchodilation following tracheal intubation in patients pre-treated with the $B_{2}$ adrenergic agonist fenoterol. 9 We found that pre-treatment produced bronchodilation that was not further supplemented by isoflurane, suggesting that fenoterol produced maximal dilation. The difference between the observation that a $\beta_{2}$ agonist is not supplemented by isoflurane and the current finding that a $\beta_{2}$ agonist does slightly supplement the effect of isoflurane may just be a reflection of sub-maximal bronchial relaxation from ten minutes of the inhaled anaesthetic alone.

Respiratory resistance declined slightly over time in the placebo group at low isoflurane concentration but not at the higher isoflurane concentration. The time dependence did not occur in the placebo group that received the higher dose of isoflurane, in whom considerable bronchodilation was achieved in the first ten minutes. The magnitude of this effect was small and there are several possibilities for why it occurred. A desensitization to the irritant effect of the tube may develop over time. Alternatively, end-tidal concentrations may not be the relevant concentration and at lower end-tidal concentrations, it may take longer to reach adequate concentrations of anaesthetic in the relevant tissue, be it smooth muscle or neural tissue. The continued decline also raises the possibility that the anaesthetic concentration in the target tissue was not yet at a steady-state, despite stability of the endtidal concentration. End tidal concentration may not reflect the concentration in tracheo-bronchial muscular and neural tissue.

Assessing dose-response data for inhaled medication can be difficult because of wide variability in particle numbers and size that reach the lungs. The spacer device used has previously been found to be highly effective in producing drug delivery similar to that expected in the non-intubated patient. ${ }^{18}$

We studied endotracheal tube-induced bronchoconstriction in a population that excluded patients requiring daily bronchodilators. Hence, we excluded the patients who might be expected to show the greatest response. However, we felt it unethical to withhold a medication required by these patients, and chose instead to study patients not normally receiving 
medication. Even apparently normal individuals develop a considerable reversible increase in $\mathrm{R}_{\mathrm{rs}}$ following intubation ${ }^{2,4}$ and patients with hyper-reactivity probably represent the extreme of this response. Although only three out of 67 of our patients gave a history of obstructive pulmonary disease, only 18 of the 67 had peak expiratory flow rates predicted, and 20 of 67 had flow rates $<80 \%$ of predicted. Thus, our population probably represents a group with greaterthan-average underlying airway obstruction, but does exclude patients at high risk for severe bronchoconstriction. Furthermore, a considerable proportion of patients with severe post-intubation bronchospasm have no previous history of airway hyperreactivity. ${ }^{1}$

Tracheal intubation produces a tracheal stimulus and is a model for studying bronchodilation, just as a pharmacological challenge with histamine or methacholine can be used to create a reproducible challenge. Because of the severity of adverse outcomes associated with bronchoconstriction, ${ }^{1}$ we have not tested this stimulus in patients with severe hyper-reactivity and implications for that population must be inferred rather than tested directly. Based on the current study, we conclude that 1 ) isoflurane has a steep doseresponse curve for bronchodilation in the 0.6-1.1 MAC range and 2) two puffs of albuterol may minimally supplement the bronchodilating effects of isoflurane under the conditions studied, but does not reduce Rrs to a level below that achieved by using isoflurane alone for a longer period of time.

\section{References}

1 Cheney FW, Posner KL, Caplan RA. Adverse respiratory events infrequently leading to malpractice suits.

Anesthesiology 1991; 75: 932-9.

2 Gal TJ. Pulmonary mechanics in normal subjects following endotracheal intubation. Anesthesiology 1980; 52: 27-35.

$3 W u R S-C, W u K C$, Tsai $Y H$, Cheng RK-S, Tan PPC. Inhaled fenoterol pretreatment attenuates airway resistance response to endotracheal intubation. Acta Anaesthesiol Sin 1995; 33: 7-14.

4 Kil H-K, Rooke GA, Ryan-Dykes $M A$, Bishop MJ. Effect of prophylactic bronchodilator treatment on lung resistance after tracheal intubation. Anesthesiology 1994; 81:43-8.

5 Hirsbman CA, Edelstein G, Peetz $S$, Wayne R, Downes $H$. Mechanism of action of inhalational anesthesia on airways. Anesthesiology 1982; 59: 107-11.

6 Tobias JD, Hirshman CA. Attenuation of histamineinduced airway constriction by albuterol during halothane anesthesia. Anesthesiology 1990; 72: 105-10.
7 Bergman NA, Waltemath $C L$. A comparison of some methods for measuring total respiratory resistance. J Appl Physiol 1974; 36: 131-4.

8 Eames WO, Rooke GA, Wu RS, Bishop MJ. Comparison of the effects of etomidate, propofol, and thiopental on respiratory resistance following tracheal intubation. Anesthesiology 1996; 84: 1307-11.

9 Heneghan CPH, Bergman NA, Jordan C, Lehane JR, Catley $D M$. Effect of isoflurane on bronchomotor tone in man. $\mathrm{Br} \mathrm{J}$ Anaesth 1986; 58: 24-8.

$10 W u R S-C, W u K-C$, Wong $T K-M$, et al. Isoflurane anesthesia does not add to the bronchodilating effect of a $\mathrm{B}_{2}$-adrenergic agonist after tracheal intubation. Anesth Analg 1996; 83: 238-41.

11 Brichant J-F, Gunst SJ, Warner DO, Rebder K. Halothane, enflurane, and isoflurane depress the peripheral vagal motor pathway in isolated canine tracheal smooth muscle. Anesthesiology 1991; 74: 325-32.

12 Korenaga S, Takeda K, Ito $\Upsilon$. Differential effects of halothane on airway nerves and muscle. Anesthesiology 1984; 60: 309-18.

13 Katoh $T$, Ikeda $K$. A comparison of sevoflurane with halothane, enflurane and isoflurane on bronchoconstriction caused by histamine. Can J Anaesth 1994; 41: 1214-9.

14 Lebane JR, Jordan C, Jones JG. Influence of halothane and enflurane on respiratory airflow resistance and specific conductance in anaesthetized man. Br J Anaesth $1980 ; 52: 773-81$.

15 Brown RH, Zerhouni EA, Hirshman CA. Comparison of low concentrations of halothane and isoflurane as bronchodilators. Anesthesiology 1993; 78: 1097-101.

16 Larsson S, Svedmyr N. Bronchodilating effect and side effects of Beta ${ }_{2}$-adrenoceptor stimulants by different modes of administration. (Tablets, metered aerosol, and combinations thereof). A study with salbutamol in asthmatics. Am Rev Resp Dis 1977; 116: 861-9.

17 Lipworth BJ, Struthers AD, McDevitt DG. Tachyphylaxis to systemic but not to airway responses during prolonged therapy with high dose inhaled salbutamol in asthmatics. Am Rev Respir Dis 1989; 140: 586-92.

18 Bishop MJ, Larson RP, Buschman DL. Metered dose inhaler aerosol characteristics are affected by the endotracheal tube actuator/adapter used. Anesthesiology $1990 ; 73: 1263-5$ 